\title{
Development of 3-methoxy-4-benzyloxybenzyl alcohol (MBBA) resin as polymer-supported synthesis support: Preparation and benzyl ether cleavage by DDQ oxidation
}

\author{
QIANG HUANG ${ }^{1, *}$, BAO-ZHONG ZHENG ${ }^{1}$ and QUAN LONG ${ }^{2}$ \\ ${ }^{1}$ Department of Materials Science and Engineering, Yunnan University, Kunming, Yunnan 650091, \\ PR China \\ ${ }^{2}$ School of Chemical Science and Engineering, Yunnan University, Kunming, Yunnan 650091, \\ PR China \\ e-mail: huangqiang@ynu.edu.cn
}

MS received 17 April 2009; revised 13 September 2009; accepted 23 December 2009

\begin{abstract}
Methoxy-4-benzyloxybenzyl alcohol (MBBA) resin was synthesized by a two-step sequence under microwave irradiation involving the reaction of commercially available Merrifield resin with vanillin, followed by reduction with sodium borohydride. MBBA resin was treated with bromides in the presence of sodium hydride to afford the corresponding resin-bound benzyl ethers. Cleavage of the resin-bound benzyl ethers from the MBBA resin was carried out using 2,3-dichloro-5,6-dicyanobenzoqunone (DDQ) to give the corresponding alcohols in good yields. Moreover, the recovery, regeneration, and reuse of this polymer support could be achieved easily. MBBA resin can be developed as a kind of solid-phase synthesis bead of alcohols.
\end{abstract}

Keywords. Solid-phase organic synthesis; polymer support; linker; 3-methoxy-4-benzyloxybenzyl alcohol resin; DDQ oxidation; recycling.

\section{Introduction}

Solid-phase organic synthesis (SPOS) continues to be important in the development of libraries of new molecules since it offers advantages such as the ease of reaction work-up and automation. ${ }^{1}$ The success of a SPOS strategy depends on the properties of the solid supports in many critical ways. ${ }^{2}$ The solid supports used most widely in SPOS are Merrifield resin and their derivatives with various linkers which are the structural bridges between the polymer framework and a substrate. Most linkers for solid-phase chemistry are derived from known protecting groups, and hereby they have been described as the immobilized protecting groups since many of them bear some similarities to protecting groups in solution phase synthesis. ${ }^{3}$ For example, they are required to be stable to the reaction conditions when used during the elaboration of the target molecule, and be cleaved selectively and orthogonally at the end of

\footnotetext{
*For correspondence
}

the synthesis, so that the target molecule can be released from the resin into solution. ${ }^{3 \mathrm{~b}, 3 \mathrm{~d}}$

On the other hand, 4-methoxybenzyl (MPM) and 3,4-dimethoxybenzyl (DMPM) protecting groups are widely applied in solution phase synthesis for their benzyl formations readily removed by 2,3 -dichloro5,6-dicyano-benzoqunone (DDQ) oxidation under mild and neutral conditions. ${ }^{4}$ Thus, one of the present authors (Zheng et al) used them skillfully for the synthesis of the complex natural products. ${ }^{5}$ Resin-bound MPM protecting groups, whose $p$ alkoxylbenzyl system could be selectively cleaved by DDQ oxidation for the release of target molecules, have been applied for SPOS of alcohols and amines. ${ }^{6}$ However, DMPM group, a more sensitive group than MPM group for DDQ removing, ${ }^{4 b}$ has not been developed for any SPOS strategies in our knowledge. In this work, we prepared a novel 3methoxy-4-benzoxybenzyl alcohol (MBBA) resin, and it was reacted with various bromides to form the benzyl ether systems which contain the resin-bound DMPM group. The benzyl ether systems cleaved by DDQ oxidation were studied for the potential application of SPOS for alcohols. 


\section{Experimental}

\subsection{Genneral}

Merrifield resin (200-400 mesh, 1\% DVB crosslinked, $1.24 \mathrm{mmolCl} / \mathrm{g}$ ) was obtained from Tianjin Nankai Hecheng Technological Com. Ltd., China, and was extracted by EtOH before it was used. Vanillin, DDQ, 4-nitrobenzyl bromide, 4-cyanobenzyl bromide, 3-bromoethyl cyanide, and $N, N$-diethyl-2bromo-acetamide were purchased from Merck, Germany. Other chemicals were obtained locally. THF and DCM were distilled before using. Microwave reactions were conducted using a CEM Discover Synthesis Unit. Reactions were performed in glass vessels. DDQ oxidation cleavages were performed using KEM-6 Parallel Synthesizer. Elemental analysis was carried out by $\mathrm{GmbH}$ Vario EL. Agilent 1100 was used for HPLC. FT-IR spectra (KBr tableting) were recorded on Thermo Nicolet TFIR AVATAR 360. ${ }^{1} \mathrm{H}-\mathrm{NMR}$ spectra were recorded using Bruker AVANCE DRX500 spectrometer with special high resolution magic angle spinning (HR-MAS) probe and the resin was placed in a $4 \mathrm{~mm}$ rotor. Chemical shifts were recorded in parts per million $(\delta: \mathrm{ppm})$ referenced to TMS $(\delta: 0)$ as an internal standard. Coupling constants $(J)$ are given in Hertz $(\mathrm{Hz})$.

\subsection{Syntheses and characterization}

2.2a 3-methoxy-4-benzoxylbenzyl aldehyde resin (1): Merrifield resin $\left(1 \mathrm{~g}, 1.24 \mathrm{mmol} \mathrm{g}^{-1}, 1.24\right.$ mmol) was placed in a reaction vessel and allowed to swell in DMF $(5 \mathrm{~mL})$ for 30 min under $\mathrm{N}_{2}$. Vanillin $(300 \mathrm{mg}, \quad 1.972 \mathrm{mmol}), \mathrm{K}_{2} \mathrm{CO}_{3} \quad(400 \mathrm{mg}$, $2.894 \mathrm{mmol})$, and tetrabutyl ammonium iodide (TBAI, $54 \mathrm{mg}, 0 \cdot 146 \mathrm{mmol}$ ) were dissolved in DMF $(15 \mathrm{~mL})$ and added via syringe to the reaction vessel. The mixture was stirred and heated in the microwave at $120^{\circ} \mathrm{C}$ for $5 \mathrm{~min}$. After cooling to room temperature, the beads were transferred to a sintered tube and washed successively with acetone- $\mathrm{CH}_{3} \mathrm{OH}-$ $\mathrm{H}_{2} \mathrm{O}(1: 1: 1)(10 \mathrm{~mL} \times 5)$, acetone $(10 \mathrm{~mL} \times 3)$, THF $(10 \mathrm{~mL} \times 3), \mathrm{CH}_{3} \mathrm{OH}(10 \mathrm{~mL} \times 3)$, then dried under vacuum at $50^{\circ} \mathrm{C}$ for one hour to give somewhat yellow beads. IR $(\mathrm{KBr}): 1688 \mathrm{~cm}^{-1}(\mathrm{C}=\mathrm{O})$, $2760 \mathrm{~cm}^{-1}(\mathrm{O}=\mathrm{C}-\mathrm{H}) .{ }^{1} \mathrm{H}-\mathrm{NMR}\left(500 \mathrm{MHz}, \mathrm{CDCl}_{3}\right): \delta$ $9.78(1 \mathrm{H}, s, \mathrm{CHO}), 7.30(2 \mathrm{H}, b r s, \mathrm{H}-\mathrm{Ar}), 6.98(\mathrm{br} s$, PS), $5.11\left(2 \mathrm{H}, b r s, \mathrm{CH}_{2} \mathrm{O}\right), 3 \cdot 70\left(3 \mathrm{H}, b r s, \mathrm{CH}_{3} \mathrm{O}\right)$, 1.73 ( $b r s$, PS), 1.38 ( $b r s$, PS). The loading of resin
(1) was determined by $\mathrm{N}$ elemental analysis involving DNP derivative reaction. Resin (1) $(20 \mathrm{mg})$ was placed in a tube and swelled in DMF (3 mL) for 15 min. DNP (3 equiv.) and a catalytic amount of acetic acid were added to the tube, then it was sealed and placed in an oscillator for $30 \mathrm{~min}$ at room temperature. The mixture was filtered, washed and dried under vacuum. Theoretical loading $=1.087 \mathrm{mmol} \mathrm{g}^{-1}$. Found: C, 78.59; H, 6.35; N, 6.06.

2.2b MBBA resin (2): Resin (1) $(992 \mathrm{mg}$, $1.081 \mathrm{mmol} \mathrm{g}^{-1}, 1.074 \mathrm{mmol}$ ) was placed in a reaction vessel and allowed to swell in THF $(5 \mathrm{~mL})$ for 30 min under $\mathrm{N}_{2} . \mathrm{NaBH}_{4}(150 \mathrm{mg}, 3.97 \mathrm{mmol})$ and TBAI ( $75 \mathrm{mg}, 0.203 \mathrm{mmol}$ ) were dissolved in mixed solvent containing THF $(10 \mathrm{~mL})$ and $\mathrm{H}_{2} \mathrm{O}(2 \mathrm{~mL})$ and the mixture was injected. The contents were stirred and heated in the microwave at reflux for $10 \mathrm{~min}$. The resultant solid was filtered, washed with ethyl acetate $(20 \mathrm{~mL})$, water $(3 \times 10 \mathrm{~mL})$, acetone $(2 \times 10 \mathrm{~mL}), \mathrm{CH}_{2} \mathrm{Cl}_{2}(2 \times 20 \mathrm{~mL})$ and ether $(2 \times 10 \mathrm{~mL})$. The resin was dried at $50^{\circ} \mathrm{C}$ for one hour to give white beads. IR (KBr): $3108,3312 \mathrm{~cm}^{-1}$. ${ }^{1} \mathrm{H}-\mathrm{NMR}\left(500 \mathrm{MHz}, \mathrm{CDCl}_{3}\right.$ ): $\delta 7 \cdot 13$ (br s, PS), 7.01 (br s, PS), 6.60 (3H br $s, \mathrm{H}-\mathrm{Ar}), 4.92(2 \mathrm{H} b r s$, $\left.\mathrm{CH}_{2} \mathrm{O}\right), 3.82\left(3 \mathrm{H}, b r s, \mathrm{CH}_{3} \mathrm{O}\right), 2.05(1 \mathrm{H}, s \mathrm{OH})$, 1.69 ( $b r s$, PS), 1.33 ( $b r s$, PS). The loading of resin (2) was determined by N elemental analysis involving 4-nitrobenzoyl chloride derivative reaction. Resin (2) $(20 \mathrm{mg})$ was placed in a tube and swelled in DMF (2 mL) for $15 \mathrm{~min}$. 4-Nitrobenzoyl chloride (3 equiv.), a catalytic amount of 4-dimethylamino pyridine (DMAP) and pyridine were added to the tube, then it was sealed and placed in an oscillator for $30 \mathrm{~min}$ at room temperature. The mixture was filtered, washed and dried under vacuum. Theoretical loading $=1.086 \mathrm{mmol} \mathrm{g}^{-1}$. Found: C, $80.13 ; \mathrm{H}$, $8 \cdot 35 ; \mathrm{N}, 1.49$.

\subsection{General procedure for the preparetion of} the resins (3a-d)

To resin (2) (200 mg, $\left.1.064 \mathrm{mmol} \mathrm{g}^{-1}, 0.210 \mathrm{mmol}\right)$ was added $\mathrm{NaH}(15.4 \mathrm{mg}, 0.642 \mathrm{mmol})$ under $\mathrm{N}_{2}$ atmosphere. One of the bromides ( 4.0 equiv.) in dry DMF $(5 \mathrm{~mL})$ was injected. The contents were shaken for $6 \mathrm{~h}$ at $60^{\circ} \mathrm{C}$. The resultant solid was filtered, washed with $\mathrm{H}_{2} \mathrm{O}(2 \times 5 \mathrm{~mL}), 3 \%$ acetic acid $(2 \times 5 \mathrm{~mL}), \quad \mathrm{H}_{2} \mathrm{O}(2 \times 5 \mathrm{~mL})$, acetone $(2 \times 5 \mathrm{~mL})$, $\mathrm{CH}_{2} \mathrm{Cl}_{2}(2 \times 5 \mathrm{~mL})$ and ether $(2 \times 5 \mathrm{~mL})$. The resins were dried in vacuum to corresponding resin-bound 


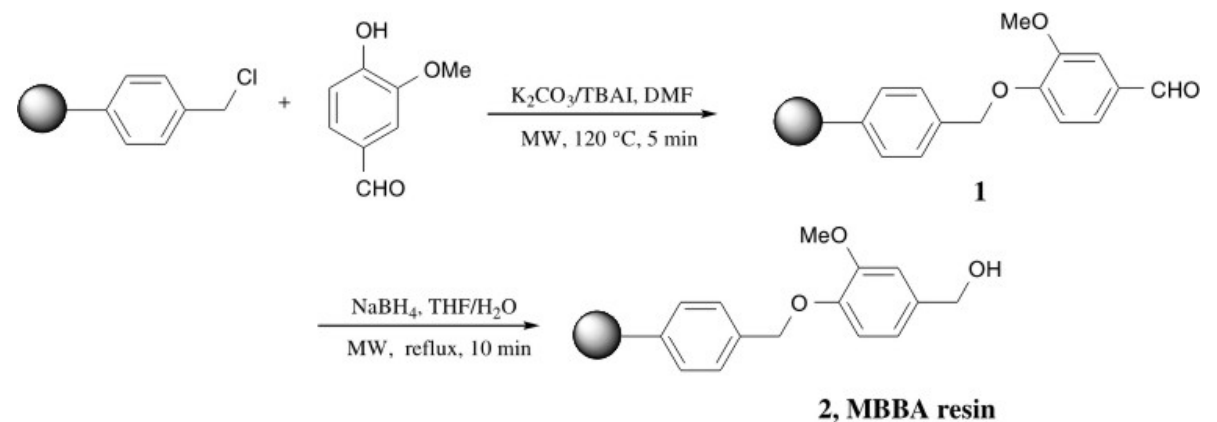

Scheme 1. The synthetic process of MBBA resin.

benzyl ethers. Theoretical loading: (3a), 0.930 mmol g ${ }^{-1}$; (3b), $\quad 0.948 \mathrm{mmol} \mathrm{g}^{-1}$; (3c), $\quad 1.007$ mmol g ${ }^{-1}$; (3d), $0.950 \mathrm{mmol} \mathrm{g}^{-1}$. Found: (3a), C, 76.52, H, 8.13, N, 1.28; (3b), C, 81.90, H, 8.46, N, 1.30; (3c), C, 78.93, H, 9.55, N, 1.36; (3d), 79.11, $10 \cdot 10, \mathrm{~N}, 1 \cdot 24$.

\subsection{General procedure for the $D D Q$ cleavage of resin-bound benzyl ethers}

To resin-bound benzyl ethers (3a-d, $200 \mathrm{mg}$ ) was respectively added DDQ ( 1.2 equiv.) in $\mathrm{CH}_{2} \mathrm{Cl}_{2}-$ $\mathrm{H}_{2} \mathrm{O}(10: 1,5 \mathrm{~mL})$. The contents were shaken for $30 \mathrm{~min}$ at room temperature. The solid was filtered, washing with $\mathrm{CH}_{2} \mathrm{Cl}_{2}-\mathrm{H}_{2} \mathrm{O}(10: 1,2 \times 5 \mathrm{~mL})$. The combined filtrate was analysed by HPLC.

\section{Results and discussion}

\subsection{Synthesis of $M B B A$ resin}

MBBA resin was prepared by a two-step sequence under microwave irradiation involving the reaction of commercially available Merrifield resin with vanillin, followed by reduction with sodium borohydride as shown in scheme 1. In the first step, Merrifield resin was reacted with vanillin in the presence of non-nucleophilic base $\mathrm{K}_{2} \mathrm{CO}_{3}$, a catalytic amount of TBAI as phase transfer catalyst, and DMF as solvent under microwave irradiation at $120^{\circ} \mathrm{C}$ only for $5 \mathrm{~min}$ as described in our previous work. $^{7}$ 3-Methoxy-4-benzoxyl benzaldehyde resin (1) was simply obtained by filtration of the reaction mixture and washing the resultant solid by various solvents. The formation of resin (1) was monitored by the appearance of $\mathrm{C}=\mathrm{O}\left(1688 \mathrm{~cm}^{-1}\right)$ and $\mathrm{O}=\mathrm{C}-\mathrm{H}$ $\left(2760 \mathrm{~cm}^{-1}\right)$ stretching frequency of polymersupported benzaldehyde group in FTIR analysis, further verified by the characteristic aldehydic reso- nance at $9.78 \mathrm{ppm}$ in the ${ }^{1} \mathrm{H}$ MAS-NMR spectrum. Loading of the aldehyde group was determined by nitrogen analysis involving 2,4-dinitrophenyl hydrazine (DNP) derivative, to be $1.081 \mathrm{mmol} / \mathrm{g}$, corresponding to $99 \%$ yield. Next, reduction of the resin (1) with $\mathrm{NaBH}_{4}$ under microwave-assisted phase transfer catalytic condition in mixed solvent $\mathrm{THF} / \mathrm{H}_{2} \mathrm{O}$ at reflux temperature for $10 \mathrm{~min}$ afforded the MBBA resin (2) according to our work reported recently. ${ }^{8}$ The monitoring of reaction was performed by the FTIR spectrum resorting the disappearance of benzaldehyde group stretching frequency and the appearance of $\mathrm{OH}$ vibrational frequency and by the ${ }^{1} \mathrm{H}$ MAS-NMR spectrum with the help of the disappearance of aldehydic resonance at $9.78 \mathrm{ppm}$. The $\mathrm{OH}$ loading of resin (2) was determined to be $1.064 \mathrm{mmol} / \mathrm{g}$ by nitrogen analysis involving 4-nitrobenzoyl chloride derivative, corresponding to $98 \%$ yield.

The syntheses of 4-benzoxylbenzyl alcohol resins have been reported earlier. ${ }^{9}$ The methoxidecatalysed displacement of benzyl chlorine of Merrifield resin by 4-hydroxybenzyl alcohol (Wang resin) ${ }^{9 a}$ or 2-methoxy-4-hydroxybenzyl alcohol (Sasrin resin) ${ }^{9 b}$ was performed. Accordingly, MBBA resin would be synthesized by the reaction of chloromethyl resin with 3-methoxy-4-hydroxybenzyl alcohol (vanillic alcohol) under the similar condition. However, we found that the target resin could hardly be attained when we prepared the MBBA resin by the reaction of commercially available Merrifield resin with vanillic alcohol under methoxidecatalysed condition. It was likely to be the instability and polymerization of $p$-hydroxy-benzyl alcohols in base. ${ }^{10}$ Furthermore, the electronic effects of the 3methoxy group of vanillic alcohol may deleteriously facilitate the polymerization in alkali medium compared with the species without methoxy group. Since the direct loading of vanillic alcohol to polymer support was unsuccessful, a relatively indirect 
method involving functional group transformation would be taken into account. Resin (1) could be readily prepared by the phase transfer catalysed reaction of Merrifield resin with vanillin in good yield. ${ }^{11}$ Vanillin being different from vanillic alcohol, the electronic effects of vanillin's $o$-methoxy group may significantly enhance the nucleophilicity of the phenolic $\mathrm{OH}$ because of the existence of formyl group, and can promote the formation of corresponding benzaldehyde resins. ${ }^{11 a}$ Then, reduction of solid-supported aldehyde to corresponding benzyl alcohol could obtain the MBBA resin (1). Though a tow-step sequence was involved in current process, the microwave irradiation assisted method could

Table 1. Etherization of (2) with bromated species

\begin{tabular}{llll}
\hline \\
$2+\mathrm{RBr}$
\end{tabular}

${ }^{a}$ With the first regenerated resin (2). ${ }^{b}$ With the second regenerated resin (2). ${ }^{\circ}$ With the third regenerated resin (2)

Table 2. Cleavage of the resin-bound benzyl ethers.

Entry

${ }^{\mathrm{a}}$ Yield according to HPLC data, product was not isolated accelerate the processing and greatly decreased the reaction time.

\subsection{Cleavage of resin-bound benzyl ethers}

Various bromides containing nitrogen, including 4nitrobenzyl bromide, $p$-cyanobenzyl bromide, 3bromoethyl cyanide, or $N, N$-diethyl-2-bromoacetamide, was respectively reacted with resin (2) in the presence of $\mathrm{NaH}$ so as to provide the corresponding polymer-supported benzyl ethers (3a-d). The separation and purification of polymersupported benzyl ethers were simply treated by filtration and washing. The loading rates of various solid-supported benzyl ethers were determined by elemental analysis. The results presented in table 1 . As can be seen, the loading rates of various benzyl ethers exceed $90 \%$, and the good loadings were obtained.

Then, the resin-bound 3-methoxy-4-benzoxylbenzyl ether systems were cleaved with DDQ (1.2 equiv.) oxidation in dichloromethane containing a small amount of water at room temperature for a quite short time to lead to formation of the corresponding alcohols (4a-d) in high yield (table 2). Comparison with the previous report of Deegan and his coworkers, ${ }^{6 a}$ the benzyl ether system of MBBA resin cleaved by DDQ exhibited similar yields though the AgroGel-Wang derived ether resins have a PEG chain spacer which makes its activity higher. ${ }^{12}$

\subsection{Regeneration and recycling}

One of the major advantages for development of the current strategy is the potential recovery of the polymer beads for subsequent reuse. The 3methoxy-4-benzoxyl benzaldehyde resin (1) could be recovered quantitatively by simple filtration and washing with organic solvents after DDQ cleavage was performed. Transmittance FTIR and ${ }^{1} \mathrm{H}-\mathrm{NMR}$ spectra of the recovered polymer beads showed the restoration of the aldehyde functional group, with a loading similar to the original value. Next, the MBBA resin (2) could be regenerated by reduction with $\mathrm{NaBH}_{4}$. The process of the regeneration and recycling for the polymer beads was schematically presented in figure 1. The $\mathrm{OH}$ loading of the first, second, and third-hand resin 2 was hardly decreased to compare that of the freshly resin, and the recovered resin could be reused for the same reactions 


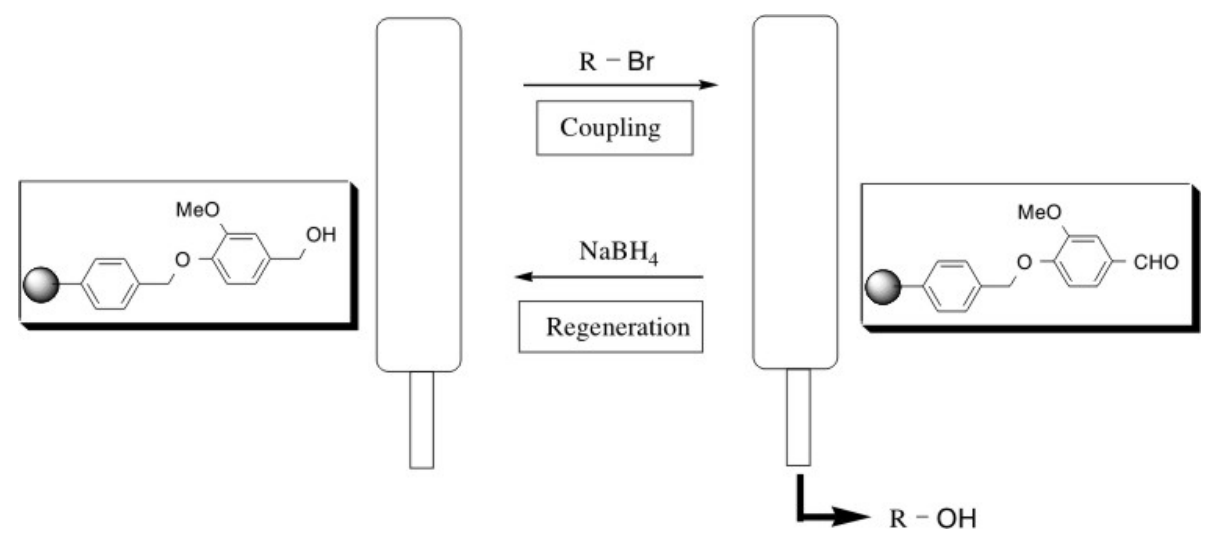

Figure 1. Repeated use of the polymer beads.

without loss of chemical yield of the resin-bound etherification products (table 1, Entry 3-5).

\section{Conclusion}

In summary, a simple and efficient two-step sequence synthesis of a novel 3-methoxy-4-benzoxylbenzyl alcohol (MBBA) resin involving linking vanillin to Merrifield resin, followed by reduction with $\mathrm{NaBH}_{4}$, and effective DDQ cleavage of solid-supported benzyl ethers were successfully carried out to obtain alcohol products. Moreover, recovery, regeneration, and reuse of the resin were achieved. In short, MBBA resin can be developed as a kind of solid-phase synthesis beads of alcohols and others, and the polymer beads can be duty-cycle operation.

\section{Acknowledgements}

We are grateful to the financial support from $\mathrm{Na}$ tional Natural Science Foundation of China (Grant No. 20172044) and Provincial Natural Science foundation of Yunnan, China (Grant No. 2005E0008Q).

\section{References}

1. (a) Boldt G E, Dickerson T J and Janda K D 2006 Drug Discovery Today 11 143; (b) Diaz-Garcia M E, Pina-Luis G and Rivero I A 2006 Trends Anal. Chem. 25 112; (c) Shimomura O, Lee B S, Meth S, Suzuki H, Mahajan S, Nomura R and Janda K D 2005 Tetrahedron 6112160

2. (a) Walsh D, Wu D and Chang Y-T 2003 Curr. Opin. Chem. Biol. 7 353; (b) Vaino A R and Janda K D 2000 J. Comb. Chem. 2 279; (c) Czarnik A W 1998 Biotechnol. Bioeng. 6177

3. (a) Guillier F, Orain D and Bradley M 2000 Chem. Rev. 100 2091; (b) Orain D, Ellard J and Bradley M
2002 J. Comb. Chem. 4 1; (c) Huang Q, Long Q and Zheng B-Z 2004 Prog. Chem. 16 236; (d) James I W 1999 Tetrahedron 55 4855; (d) Brown A R, Hermkens P H H, Ottenheijm H C J and Rees D C 1998 Synlett 817

4. (a) Oikawa Y, Yoshioka T and Yonemistu O 1982 Tetrahedron Lett. 23 885; (b) Horyta K, Yoshioka T, Tanaka T, Oikawa Y and Yonemistu O 1986 Tetrahedron. 423021

5. (a) Zheng B-Z, Yamauchi M, Dei H, Kusaka S, Matsui $\mathrm{K}$ and Yonemitsu O 2000 Tetrahedron Lett. 41 6441; (b) Matsui K, Zheng B-Z, Kusaka S, Kuroda M, Yoshimoto K, Yamada H and Yonemitsu O 2001 Eur. J. Org. Chem. 3615; (c) Zheng B-Z, Maeda H, Mori M, Kusaka S, Matsushima T, Nakajima N, Uenishi J and Yonemitsu O 1999 Chem. Pharm. Bull. 47 1288; (d) Zheng B-Z, Yamauchi M, Dei $\mathrm{H}$ and Yonemitsu O 2000 Chem. Pharm. Bull. 481761

6. (a) Deegan T L, Gooding O W, Baudart S and Porco J A 1997 Tetrahedron Lett. 38 4973; (b) Kobayashi S and Aoki Y 1998 Tetrahedron Lett. 39 7345; (c) Kobayashi S and Akiyama R 1998 Tetrahedron Lett. 399211

7. Huang Q, Li Z, Ma X, Long Q and Zheng B-Z 2007 Acta Polym. Sin. 7681

8. Huang Q, Long Q and Zheng B-Z 2008 Acta Polym. Sin. 5487

9. (a) Lu G S, Mojsov S, Tam J P and Merrifield R B $1981 \mathrm{~J}$. Org. Chem. 46 3433; (b) Mergler M, Tanner $\mathrm{R}$, Gosteli J and Grogg P 1988 Tetrahedron Lett. 32 4005

10. Katritzky A R, Toader D, Watson K and Kiely J S 1997 Tetrahedron Lett. 387849

11. (a) Sarhan A A, El-Shehawy A A and Abdelaal M Y 2002 React. Funct. Polym. 50 139; (b) Huang Q, Long Q, Shi M X and Zheng B-Z 2005 Chin. J. Funct. Polym. 1832

12. (a) Porco J A, Deedan T, Devonport W, Gooding O W, Heisler K, Labadie J W, Newcomb B, Nguyen C, van Eikeren $\mathrm{P}$, Wong $\mathrm{J}$ and Wright $\mathrm{P} 1997 \mathrm{Mol}$. Divers. 2 197; (b) Cardona C M, Jannach S H, Huang H, Itojima Y, Leblam R M and GamLey R E 2002 Helv. Chim. Acta $\mathbf{8 5} 3532$ 